\title{
Characterization of Egyptian Cotton Fiber Quality Using CCS
}

\author{
Mona El-Sayed Shalaby, Ibrahim Ahmed Ebaido, and Yasser Shokry Abd-El-Rahman
}

\section{ABSTRACT}

The purpose of the current study is to characterize Egyptian cotton using HVI and CCS measurements. The present investigation was carried out at two different locations: The Global Center for Cotton Testing Research in International Cotton Association (ICA) using HVI instrument in Germany and Egyptian and International Cotton Classification Center (EICCC), Cotton Research Institute (CRI), Agricultural Research Center (ARC) using CCS instrument in Egypt. Samples are sourced from standardized preparation stages to obtain more homogeneity. All samples were collected from 2018 and 2019 cotton growing seasons. The studied cotton fiber properties: upper half mean (UHM), uniformity index (UI \%), short fiber index (SFI \%), strength (FS) and elongation (E \%) and micronaire reading (Mike) and maturity ratio (MR). The studied cotton varieties include long staple cotton varieties i.e., Giza 86 and Giza 95 and extra-long staple cotton varieties i.e., Giza 92 and Giza 93, in terms of basic Egyptian cotton grade Good (G). The results of HVI and CCS measurements were detected by using descriptive statistics such as measures of central tendency and dispersion, skewness, and kurtosis. The CCS measurements were more stable than HVI measurements. Confidence intervals of CCS measurements were close to each other compared to HVI measurements. For instance, in Giza 92, confidence interval of UHM was 32.00-32.32for HVI and 32.50-32.55for CCS, adding to confidence intervals for FS were 45.19-46.83for HVI and 46.99-47.17 for CCS. Meanwhile, confidence intervals for Mike were 3.04-3.21 for HVI and 3.12-3.14 for CCS. Basically, sample sizes of CCS were larger more than sample sizes of HVI so that results of CCS measurements were more homogenous than HVI measurements. Applying reliability analysis for consistent results in CCS and HVI measurements elaborated Cronbach's value were more efficient than using Cronbach's value if item deleted for both CCS and HVI. Cronbach's value of CCS measurements was more than HVI measurements and that due to the homogeneity of CCS samples compared to HVI samples.

Keywords: cotton fiber properties, Confidence interval, Descriptive statistics, Reliability analysis, CCS and HVI.

\section{INTRODUCTION}

Egyptian cotton has not gained such a reputation without reason. Egyptian cotton is the world's finest cotton. According to Global Agricultural Information Network [10]; the fiber characteristics are what set Egyptian cotton apart from other natural fibers, some of them as following bellow:

1. Fiber length makes it possible to make the finest of yarns without sacrificing the strength of yarns.

2. Fiber strength makes fabrics more solid and more resistant to stress.

Adding to that Egyptian cotton is handpicked which guarantees the highest levels of purity. Also, hand picking puts no stress on cotton fibers as opposed to mechanical picking-leaving the fibers straight, intact, softness feels like nothing else in the world and ability to absorb liquids gives fabrics made of Egyptian cotton deeper, brighter and more resistant colors.
Published Online: January 16, 2021

ISSN: $2684-1827$

DOI: 10.24018 /ejfood.2021.3.1.174

Mona El-Sayed Shalaby*

(e-mail: moonytato@yahoo.com)

Ibrahim Ahmed Ebaido

(e-mail: drbado@yahoo.com)

Yasser Shokry Abd-El-Rahman

*Corresponding Author

All these factors have resulted in the Egyptian cotton being by far the best cotton in the world. Fabrics made of Egyptian cotton are softer, finer and last longer than any other cotton in the world.

Reference [4] exhibited that fiber classing technologies now in use and under development and evaluation allow quantization of fiber properties, application of improved standards for end product quality and system of fiber quality measurements that can be manful and useful for producers and processors alike. More details about fiber producers and fiber processors in corporate fiber and materials methodology [6].

The main target of economical cotton planting is to ensure marketing and optimizing utilization of cotton fibers which required highly standardization according to Guideline for standardized instrument testing of cotton [11]

Reference [5] elucidated that fiber yield is easily quantified in bales per acre, but fiber quality is a complex of both quantitative and qualitative properties like fiber length, length uniformity, fineness, and maturity (measured as 
micronaire reading), strength and other quality properties. Measurement of fiber quality is further complicated by significant natural and environment related variations for several cotton development stages. Furthermore, improvement in fiber quality will be best to achieve optimization of the bulk fiber properties determined during cotton classing and through increasing fiber quality uniformity.

Fiber length is considered the premier fiber quality attribute because staple length is closely correlated with processing efficiency and the quality of yarn produced so cotton breeders work to improve it [18] and [20]. Accurate measurement of the short fiber content of a collection of fibers is dependent on the basic measurements of fiber length by any instrument under considerations. Where the measurement of short fiber content is a part of overall task of fiber length distribution measurements [31].

Reference [17] elaborated details of the fiber elongation percentage and fiber strength where both of them help to determine the total energy needed to break a bundle of fibers. They play important role in almost all of the textile manufacturing processes.

Reference [24] illustrated the different instruments for micronaire reading and they insisted and proved that micronaire is a key cotton fiber quality assessment property, and changes in fiber micronaire can impact fiber processing and dyeing consistency. Cotton fiber quality characteristics are measured in a laboratory under tightly controlled environmental conditions. There is increased interest by the cotton and textile industry to measure fiber properties both in the laboratory and in field (non-controlled conditions) using several different instruments.

Various instruments have been developed for commercial use that attempt to quickly and easily measure cotton quality properties with more available and when such technology becomes more automated and more precisely assessed quality.

TEXTECHNO Company designed a new generation of Medium Volume Instrument (MVI) - called Cotton Classifying System (CCS) to determine micronaire value and maturity, fiber length distribution, tensile strength and elongation and other several properties. The CCS system consists of several testing stations such as Fibrotest for length and strength, Wira for fineness and maturity, FMT for trash and Opotest for color and grade attributes. The advantage of this structure is that if the need is one station in process or in case one station damaged the other stations still can be used [30] and [35].

Some of the merits of CCS system:

1. It is applicable for raw cotton in order to classify cotton as well as for sliver and roving in order to perform tests for technological testing during spinning process in order to assess the spinnability.

2. The operation can be done by one operator only. Operator should have a basic knowledge about fiber as well as he should understand to operate a PC.

This work aimed to standardize the commercial Egyptian cotton using CCS.

\section{MATERIAls AND METHODS}

The used study materials include four cotton varieties: long staple category (Giza 86 (G 86) and Giza 95 (G 95)) and extra-long staple class (Giza 92(G 92) and Giza 93 (G 93 ) in terms of the basic Egyptian cotton grade Good (G). All used samples were collected from 2018 and 2019 cotton growing seasons.

Data of fiber properties in the studied cotton varieties were measured at two locations: the first one was in the Global Center for Cotton Testing Research in international Cotton Association (ICA) using USTER HVI 1000, Bremen, Germany and the second one was in Egyptian \& International Cotton Classification Center (EICCC), Cotton Research Institute (CRI), Agricultural Research Center (ARC) using Cotton Classifying System (CCS).

Fiber properties studied include, fiber length parameters, i.e., Upper Half Mean Length (UHM), Uniformity index (UI \%), and Short fiber index (SFI \%), fiber strength parameter, i.e., elongation (E \%) and Strength (FS) and fiber fineness and maturity; maicronaire reading (Mike) and maturity ratio (MR).

For preparation of standards, the basic cotton is sourced from breeding department of cotton research institute at ARC ensuring high purity of seed with best practices and all process preparation such as opening, cleaning and ginning after that cotton is processed ensuring homogenous mixing of fibers by collecting randomly from the processed lot. Homogeneous sample sizes provide a powerful tool for the selected different parts of cotton bales and the final selected cotton samples.

All samples were conducted under standard testing conditions of $20 \pm 2{ }^{\circ} \mathrm{C}$ temperature and $65 \pm 2 \%$ relative humidity; ASTM [1]. At the premises of Textile Testing Technology, the Cotton Classifying System (CCS) designed to measure all fiber properties.

Descriptive statistics analyses were calculated and elucidated [29].

The confidence statement: [29] and [32].

The check of confidence statements based on the samples to see if the stated confidence is justified. For each random sample and $95 \%$ level of probability, a confidence interval is established about the sample mean.

Reliability analysis: [7]

Internal consistency reliability is used to measure the reliability of a summated scale where several items are summed to form a total score.

Minitab [9] and SPSS [27] software was used for all statistical analyses.

\section{RESULTS}

Studying descriptive statistics such as center of data, spread of data, skewness and kurtosis for G 86, G 95, G 92 and $\mathrm{G} 93$ are shown in Tables 1, 2, 3 and 4 .

Mean is a standard measure of the center of the distribution of the data. Median and mean both measure central tendency. But unusual values which are measured by Trimmed mean (Tr. Mean) called outliers where more obvious relation with median other than means. Then using both mean and median is better measure to use. If the data 
are symmetric; mean and median are close. Meanwhile the data appear to the right which explains why mean is greater than median [8] and [14].

For HVI measurements, Tables 1, 2, 3 and 4 showed the equal measures of both mean and median to UI\% for both $\mathrm{G}$ 86 and $\mathrm{G} 93$, the same equality was in UHM and E\% for G 92 and MR for G 93. Meanwhile, in CCS measurement there were differences between mean and median but in small limit and that may be due to that the number of samples in HVI measurements were less than the samples in CCS measurements. The differences were in decimals not in large integer numbers where those were obtained from the homogeneous several operation steps till received the studied samples for both HVI and CCS measurements. Reference [13] found out one of the several advantages from using larger samples; provide more precise estimates of the process parameters such as mean and standard deviations.

Using homogeneous samples illustrated the similar values for Tr. mean and mean for HVI measurements except in Mike for G 93 in Tables 1, 2, 3 and 4. Meanwhile Tr. Mean was more or less than mean for all cotton quality properties in CCS measurements. Furthermore, there were a fluctuation between equality, increasing or decreasing between Tr. Mean and median in HVI measurements. Meanwhile in CCS Tr. Mean equal median for almost studied properties except in E \% for G 86 and G 92, UI\% and MR for G 92 and UHM, SFI and E\% for G 93.

Coefficient of variation (C.V.) is determined how spread out of data is from mean. In results, almost C.V. for HVI measurements had much variation compared to CCS measurements. According to the used sample sizes of them.

Skewness and kurtosis involve the tails of the distribution. Skewness is a measure of the symmetry in a distribution. A symmetrical data set will have a skewness equal to zero. So, a perfect normal distribution will have a skewness of zero such as in E\% for G 92 and MR for G 93 in HVI measurements. In Tables 3 and 4. Skewness essentially measures the relative size of the two tails. Where values of almost cotton properties in HVI measurements were less than CCS measurements except for UHM and SFI\% for G 86, SFI for G 95 and (E\% and FS) for G 93. Above to all, maturity ratio (MR) of HVI measurements was more than CCS measurements except in G 92. Kurtosis is a measure of combined sizes of the two tails. It measures the amount of probability in the tails. The value is often compared to the kurtosis of the normal distribution which is equal to 3 which is called meso-kurtosis. If the kurtosis is greater than 3 which are called lepto-kurtosis, then the data set has heavier tails than a normal distribution which has less in tails.

TABLE I: CENTER AND SPREAD OF DATA AND TAILS OF DiSTRIBUTION FOR COTTON FIBER PROPERTIES IN GIZA 86

\begin{tabular}{|c|c|c|c|c|c|c|c|c|c|c|c|c|}
\hline \multicolumn{7}{|c|}{ Center of data } & \multirow{2}{*}{\multicolumn{2}{|c|}{$\frac{\text { Spread of data }}{\text { C.V. }}$}} & \multicolumn{4}{|c|}{ Tails of distribution } \\
\hline \multirow{2}{*}{ Traits } & \multicolumn{2}{|c|}{ Mean } & \multicolumn{2}{|c|}{ Tr. Mean } & \multicolumn{2}{|c|}{ Median } & & & \multicolumn{2}{|c|}{ Skewness } & \multicolumn{2}{|c|}{ Kurtosis } \\
\hline & HVI & CCS & HVI & CCS & HVI & CCS & HVI & $\mathrm{CCS}$ & HVI & $\mathrm{CCS}$ & HVI & CCS \\
\hline UHM & 30.98 & 31.69 & 30.98 & 31.70 & 31.10 & 31.70 & 1.61 & 0.13 & -1.99 & -6.90 & 4.33 & 47.42 \\
\hline $\mathrm{UI} \%$ & 84.60 & 84.28 & 84.60 & 84.25 & 84.60 & 84.25 & 0.46 & 0.22 & -0.36 & 8.33 & -0.13 & 72.76 \\
\hline SFI $\%$ & 7.63 & 7.20 & 7.63 & 7.23 & 7.65 & 7.23 & 3.58 & 2.40 & -0.43 & -6.90 & 0.59 & 47.42 \\
\hline $\mathrm{E} \%$ & 5.86 & 5.42 & 5.86 & 5.41 & 5.90 & 5.40 & 2.33 & 1.86 & -0.52 & 5.20 & -1.87 & 30.50 \\
\hline FS & 41.11 & 41.10 & 41.11 & 41.10 & 41.00 & 41.10 & 1.12 & 0.38 & 0.39 & 1.94 & -0.32 & 30.63 \\
\hline Mike & 4.57 & 4.52 & 4.57 & 4.52 & 4.56 & 4.52 & 0.46 & 0.31 & 1.7 & 10.00 & 3.66 & 100.0 \\
\hline MR & 87.83 & 88.31 & 87.83 & 88.35 & 88.00 & 88.35 & 0.46 & 0.29 & -2.45 & -8.09 & 6.00 & 86.44 \\
\hline
\end{tabular}

TABLEII: CENTER AND SPREAD OF DATA AND TAILS OF DISTRIBUTION FOR COTTON FIBER PROPERTIES IN GIZA 95

\begin{tabular}{|c|c|c|c|c|c|c|c|c|c|c|c|c|}
\hline \multicolumn{7}{|c|}{ Center of data } & \multirow{2}{*}{\multicolumn{2}{|c|}{$\begin{array}{c}\text { Spread of data } \\
\text { C.V. }\end{array}$}} & \multicolumn{4}{|c|}{ Tails of distribution } \\
\hline \multirow{2}{*}{ Traits } & \multicolumn{2}{|c|}{ Mean } & \multicolumn{2}{|c|}{ Tr. Mean } & \multicolumn{2}{|c|}{ Median } & & & \multicolumn{2}{|c|}{ Skewness } & \multicolumn{2}{|c|}{ Kurtosis } \\
\hline & HVI & CCS & HVI & $\mathrm{CCS}$ & HVI & $\mathrm{CCS}$ & HVI & $\mathrm{CCS}$ & HVI & $\mathrm{CCS}$ & HVI & $\mathrm{CCS}$ \\
\hline UHM & 28.45 & 29.56 & 28.45 & 29.50 & 28.92 & 29.50 & 5.25 & 0.24 & -2.06 & 5.45 & 4.59 & 29.43 \\
\hline $\mathrm{UI} \%$ & 80.93 & 82.28 & 80.93 & 82.30 & 80.95 & 82.30 & 0.51 & 0.66 & -0.02 & 2.85 & -2.79 & 39.85 \\
\hline SFI\% & 9.56 & 8.07 & 9.56 & 8.12 & 9.65 & 8.12 & 3.22 & 2.74 & -0.70 & -4.70 & -0.93 & 21.14 \\
\hline $\mathrm{E} \%$ & 7.26 & 7.01 & 7.26 & 7.00 & 7.30 & 7.00 & 2.07 & 1.22 & -1.27 & 5.68 & 1.53 & 31.25 \\
\hline FS & 33.83 & 33.07 & 33.83 & 33.00 & 33.90 & 33.00 & 1.91 & 1.62 & -0.48 & 8.47 & 0.68 & 75.15 \\
\hline Mike & 3.54 & 3.55 & 3.54 & 3.55 & 3.54 & 3.55 & 0.33 & 0.31 & 0.60 & 10.00 & -0.45 & 100.00 \\
\hline MR & 84.07 & 84.51 & 84.07 & 84.52 & 84.05 & 84.52 & 0.10 & 0.11 & 0.60 & -2.3 & -0.98 & 30.97 \\
\hline
\end{tabular}

TABLE III: CENTER AND SPREAD OF DATA AND TAILS OF DISTRIBUTION FOR COTTON FIBER PROPERTIES IN GIZA 92

\begin{tabular}{|c|c|c|c|c|c|c|c|c|c|c|c|c|}
\hline \multicolumn{7}{|c|}{ Center of data } & \multirow{2}{*}{\multicolumn{2}{|c|}{$\begin{array}{c}\text { Spread of data } \\
\text { C.V. }\end{array}$}} & \multicolumn{4}{|c|}{ Tails of distribution } \\
\hline \multirow{2}{*}{ Traits } & \multicolumn{2}{|c|}{ Mean } & \multicolumn{2}{|c|}{ Tr. Mean } & \multicolumn{2}{|c|}{ Median } & & & \multicolumn{2}{|c|}{ Skewness } & \multicolumn{2}{|c|}{ Kurtosis } \\
\hline & HVI & $\mathrm{CCS}$ & HVI & $\mathrm{CCS}$ & HVI & $\mathrm{CCS}$ & HVI & $\mathrm{CCS}$ & HVI & $\mathrm{CCS}$ & HVI & $\mathrm{CCS}$ \\
\hline UHM & 32.16 & 32.53 & 32.16 & 32.50 & 32.16 & 32.50 & 0.46 & 0.37 & 0.10 & 3.76 & -1.49 & 12.40 \\
\hline $\mathrm{UI} \%$ & 84.28 & 84.33 & 84.28 & 84.32 & 84.30 & 83.80 & 0.60 & 0.73 & -0.97 & 0.36 & 1.80 & -1.58 \\
\hline $\mathrm{SFI} \%$ & 7.58 & 7.18 & 7.58 & 7.20 & 7.55 & 7.20 & 3.05 & 1.67 & 0.30 & -10.00 & -1.42 & 100.00 \\
\hline $\mathrm{E} \%$ & 5.10 & 5.03 & 5.10 & 5.03 & 5.10 & 5.00 & 1.24 & 0.95 & 0 & 0.64 & 2.50 & -1.63 \\
\hline FS & 46.01 & 47.08 & 46.01 & 47.00 & 45.90 & 47.00 & 1.70 & 0.93 & 1.20 & 5.48 & 1.55 & 30.03 \\
\hline Mike & 3.42 & 3.44 & 3.42 & 3.40 & 3.99 & 3.40 & 2.50 & 1.13 & -2.41 & 4.40 & 5.83 & 18.44 \\
\hline MR & 84.28 & 84.57 & 84.28 & 84.55 & 84.30 & 84.50 & 0.33 & 0.21 & 0.01 & 1.99 & -2.94 & 2.00 \\
\hline
\end{tabular}


TABLE IV: CENTER AND SPREAD OF DATA AND TAILS OF DISTRIBUTION FOR COTTON FIBER PROPERTIES IN GIZA 93

\begin{tabular}{|c|c|c|c|c|c|c|c|c|c|c|c|c|}
\hline \multicolumn{7}{|c|}{ Center of data } & \multirow{2}{*}{\multicolumn{2}{|c|}{$\begin{array}{c}\text { Spread of data } \\
\text { C.V. }\end{array}$}} & \multicolumn{4}{|c|}{ Tails of distribution } \\
\hline \multirow{2}{*}{ Traits } & \multicolumn{2}{|c|}{ Mean } & \multicolumn{2}{|c|}{ Tr. Mean } & \multicolumn{2}{|c|}{ Median } & & & \multicolumn{2}{|c|}{ Skewness } & \multicolumn{2}{|c|}{ Kurtosis } \\
\hline & HVI & CCS & HVI & $\mathrm{CCS}$ & HVI & $\mathrm{CCS}$ & HVI & $\mathrm{CCS}$ & HVI & CCS & HVI & $\mathrm{CCS}$ \\
\hline UHM & 33.96 & 34.06 & 33.96 & 34.02 & 33.99 & 33.99 & 0.87 & 0.66 & -0.54 & 2.91 & 1.36 & 6.59 \\
\hline $\mathrm{UI} \%$ & 83.90 & 85.02 & 83.90 & 85.00 & 83.90 & 85.00 & 0.73 & 0.47 & 0.23 & 3.01 & -0.73 & 17.67 \\
\hline SFI\% & 6.48 & 6.53 & 6.48 & 6.56 & 6.45 & 6.60 & 3.57 & 3.08 & 0.30 & -2.90 & -1.42 & 6.59 \\
\hline $\mathrm{E} \%$ & 5.46 & 5.37 & 5.46 & 5.39 & 5.45 & 5.40 & 2.22 & 1.91 & -0.08 & -3.42 & -1.55 & 9.914 \\
\hline FS & 41.00 & 42.93 & 41.00 & 42.99 & 41.10 & 42.99 & 1.61 & 0.79 & -0.50 & -5.59 & -0.59 & 29.90 \\
\hline Mike & 3.40 & 3.51 & 3.48 & 3.50 & 3.54 & 3.50 & 1.02 & 0.49 & -0.2 & 6.66 & -1.86 & 44.91 \\
\hline MR & 83.50 & 84.66 & 83.50 & 84.66 & 83.50 & 84.66 & 0.66 & 0.26 & 0 & -2.08 & -3.33 & 46.95 \\
\hline
\end{tabular}

Lepto-kurtosis were shown in Tables 1, 2, 3 and 4 for HVI measurements in UHM in G 86 and G 95, MR for G86 and Mike for both of G 86 and G 92. In spite of all rest of variables were shown as platy-kurtosis (less than 3). Furthermore, in CCS measurements properties were leptokurtosis for all cotton quality properties except in UI\%, E\% and MR for G 92 only. So, it is obvious that studying large sample sizes as in CCS measurements give the opportunity to get more accurate explanation for a large field of observations by the normal distribution shape more than small sample size such as in HVI measurements gave short range of explanation according to a smaller number of the used observations. The skewness and kurtosis statistics appear to be very dependent on the sample size. Smaller sample sizes can give results that are very misleading which are in agreement with [16] and [33].

Graphically, histogram of data with normal curve illustrated by Fig. 1, 2, 3 and 4. In uniformity index (UI \%) for G 86 using HVI instrument; Fig. 1 showed the bell shaped (equality among mean, Tr. mean and median), negative skewness (-0.36) which illustrated close to symmetry distribution meanwhile measure of kurtosis $(-0.13)$ showed that the dataset has lighter tails than a normal distribution (it's tails are shorter and thinner and central peak is lower and broader). Fig. 2 elaborated Mike for G 86 using CCS which is close to bell shaped (nearly close to each other; Tr. mean equals median meanwhile mean is more than them by 0.001) meanwhile skewness (10) was highly skewed and kurtosis (100) tails' longer and flatter and central peak is higher and sharper.

Fig. 3 elaborated elongation percentage (E \%) using HVI instrument for G 92; normal bell shaped $($ mean $=$ median $=$ Tr. mean), symmetric skewness (0) with nearly mesokurtic (2.5). In spite of Fig. 4 showed the equality of mean, Tr. mean and median (normal bell shaped) with symmetric skewness (0) and platykurtosis (-3.33) in maturity ratio (MR) using CCS instrument for G 95 .

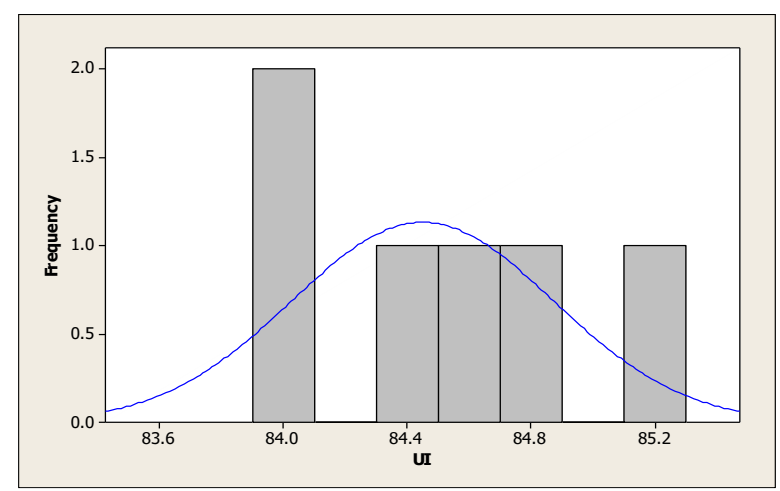

Fig. 1. Dataset with negative skewness andkurtosis for G 86 in HVI measurements.

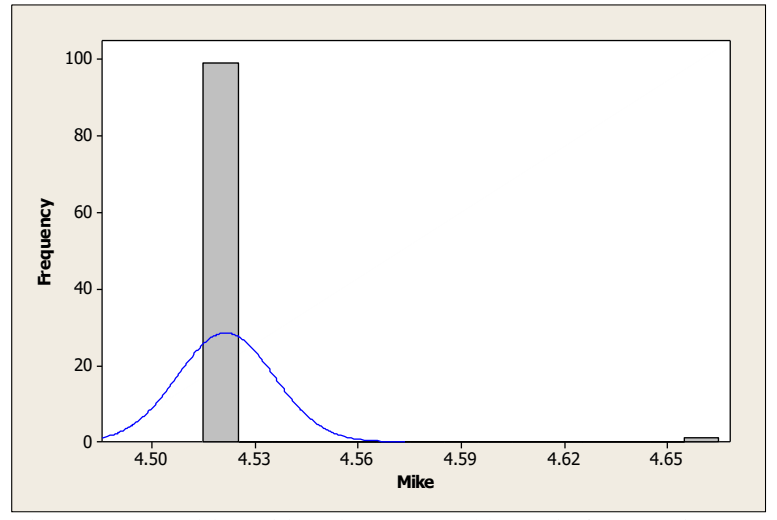

Fig.2. Dataset with positive skewness and kurtosis for G 86 in CCS measurements.

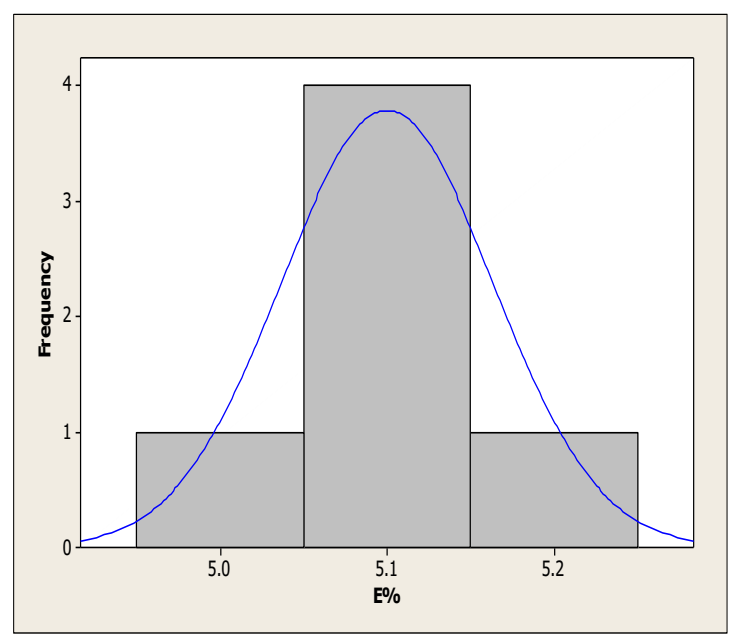

Fig.3. Dataset with zero skewness and positive kurtosis for G 92 in HVI measurements.

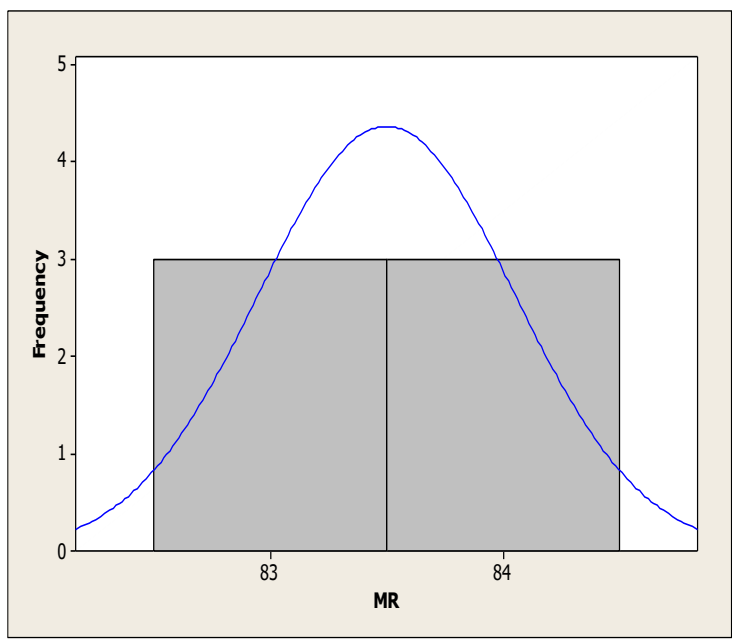

Fig.4. Dataset with zero skewness and negative kurtosis for G 95 in CCS measurements. 
Central tendency (mean, median and tr. mean), measure of dispersion (C.V.), skewness and kurtosis statistics appear to be very dependent on the sample size. Smaller sample sizes can give misleading results. These results in agreement with [33].

P-values are used to determine whether a null hypothesis formulated before performance of the study is to be accepted or rejected. P-value is calculated to assess whether the difference or the result is by chance or not. P-value simply provides a cut-off beyond which we assess the studied properties is not significant. However, the results of a statistical testing are highly influenced by standard deviation (the sample variability within sample).

According to Tables 5, 6, 7 and 8, a t-value of 0 or close to 0 indicates that the cotton fiber properties results exactly equal the null hypothesis. As the differences between the sample data and the null hypothesis increase, the absolute value of the t-value increases. Interpretation of results based only on $\mathrm{P}$ values can be misleading. Confidence interval conveys more information than $\mathrm{P}$ values. It provides magnitude of effect as well as its variability. Confidence interval (CI) should be calculated for all cotton fiber properties especially if $\mathrm{P}$ values are insignificant. The same trend of results was detected by [12].

CI provides information about a range in which the true value lies with a certain degree of probability $95 \%$. Increasing the sample size decreases the width of confidence interval for the population mean [2], [3] and [25]. Tables 5, 6, 7 and 8 elaborated that narrow width of CI for HVI and CCS measurements means there is small range of effect size in the study indicates that size is quite large since the range of effect is narrow and hence the study has reasonable certainty. Wide or diverse range of effect size and hence the estimate is not precise. The same trend of results was by [14] and [26].

TABLE V: RELATIONSHIP OF P-VALUE WITH STANDARD DEVIATION AND CONFIDENCE INTERVALS FOR GIZA 86

\begin{tabular}{|c|c|c|c|c|c|c|c|c|c|c|}
\hline \multirow[b]{2}{*}{ Traits } & \multicolumn{5}{|c|}{ HVI } & \multicolumn{5}{|c|}{$\mathrm{CCS}$} \\
\hline & $\begin{array}{l}\text { Lower } \\
95 \% \text { CI }\end{array}$ & $\begin{array}{c}\text { Upper } 95 \% \\
\text { CI }\end{array}$ & $\begin{array}{l}\text { Standard } \\
\text { deviation }\end{array}$ & $\mathrm{T}$ & $\mathrm{P}$ & $\begin{array}{l}\text { Lower } \\
95 \% \text { CI }\end{array}$ & $\begin{array}{c}\text { Upper } 95 \% \\
\text { CI }\end{array}$ & $\begin{array}{l}\text { Standard } \\
\text { deviation }\end{array}$ & $\mathrm{T}$ & $P$ \\
\hline UHM & 30.46 & 31.51 & 0.500 & 0 & 0.999 & 31.68 & 31.70 & 0.0422 & 0 & 1 \\
\hline $\mathrm{UI} \%$ & 84.19 & 85.00 & 0.390 & 0 & 1 & 84.24 & 84.31 & 0.1889 & 0 & 0.995 \\
\hline $\mathrm{SFI} \%$ & 7.34 & 7.92 & 0.273 & 0 & 0.998 & 7.17 & 7.24 & 0.1732 & 0 & 0.999 \\
\hline $\mathrm{E} \%$ & 5.72 & 6.01 & 0.136 & 0 & 1 & 5.40 & 5.44 & 0.1011 & 0 & 0.999 \\
\hline FS & 40.63 & 41.60 & 0.462 & 0 & 0.999 & 41.07 & 41.13 & 0.0157 & 0.01 & 0.989 \\
\hline Mike & 4.54 & 4.59 & 0.020 & 0 & 1 & 4.51 & 4.52 & 0.0140 & 0 & 1 \\
\hline
\end{tabular}

TABLE VI: RELATIONSHIP OF P-VALUE WITH STANDARD DEVIATION AND CONFIDENCE INTERVALS FOR GIZA 95

\begin{tabular}{|c|c|c|c|c|c|c|c|c|c|c|}
\hline \multirow[b]{2}{*}{ Traits } & \multicolumn{5}{|c|}{ HVI } & \multicolumn{5}{|c|}{ CCS } \\
\hline & $\begin{array}{l}\text { Lower } \\
95 \% \text { CI }\end{array}$ & $\begin{array}{c}\text { Upper } 95 \% \\
\text { CI }\end{array}$ & $\begin{array}{l}\text { Standard } \\
\text { deviation }\end{array}$ & $\mathrm{T}$ & $\mathrm{P}$ & $\begin{array}{c}\text { Lower } \\
95 \% \mathrm{CI}\end{array}$ & $\begin{array}{c}\text { Upper } 95 \% \\
\text { CI }\end{array}$ & $\begin{array}{r}\text { Standard } \\
\text { deviation }\end{array}$ & $\mathrm{T}$ & $\mathrm{P}$ \\
\hline UHM & 28.89 & 30.02 & 1.4940 & 0 & 1 & 29.54 & 29.57 & 0.0723 & 0.03 & 0.978 \\
\hline SFI\% & 9.24 & 9.89 & 0.3080 & 0 & 0.998 & 8.03 & 8.12 & 0.2212 & 0 & 0.999 \\
\hline $\mathrm{E} \%$ & 7.10 & 7.42 & 0.1506 & 0 & 1 & 6.99 & 7.03 & 0.0856 & 0 & 1 \\
\hline FS & 33.15 & 34.51 & 0.6470 & 0 & 0.999 & 32.96 & 33.17 & 0.5366 & 0 & 1 \\
\hline Mike & 3.53 & 3.55 & 0.0117 & 0 & 1 & 3.55 & 3.59 & 0.0112 & 0 & 0.989 \\
\hline MR & 83.98 & 84.16 & 0.0876 & 0.01 & 0.993 & 84.49 & 84.53 & 0.0888 & 0.04 & 0.968 \\
\hline
\end{tabular}

TABLEVII: RELATIONSHIP OF P-VALUE WITH STANDARD DEVIATION AND CONFIDENCE INTERVALS FOR GIZA 92

\begin{tabular}{|c|c|c|c|c|c|c|c|c|c|c|}
\hline \multirow[b]{2}{*}{ Traits } & \multicolumn{5}{|c|}{ HVI } & \multicolumn{5}{|c|}{$\mathrm{CCS}$} \\
\hline & $\begin{array}{l}\text { Lower } \\
95 \% \text { CI }\end{array}$ & $\begin{array}{c}\text { Upper } 95 \% \\
\text { CI }\end{array}$ & $\begin{array}{l}\text { Standard } \\
\text { deviation }\end{array}$ & $\mathrm{T}$ & $\mathrm{P}$ & $\begin{array}{l}\text { Lower } \\
95 \% \text { CI }\end{array}$ & $\begin{array}{c}\text { Upper } 95 \% \\
\text { CI }\end{array}$ & $\begin{array}{l}\text { Standard } \\
\text { deviation }\end{array}$ & $\mathrm{T}$ & $\mathrm{P}$ \\
\hline UHM & 32.00 & 32.32 & 0.1494 & 0.01 & 0.996 & 32.50 & 32.55 & 0.1193 & 0 & 1 \\
\hline SFI\% & 7.34 & 7.82 & 0.2317 & 0 & 1 & 7.16 & 7.21 & 0.1200 & 0 & 1 \\
\hline $\mathrm{E} \%$ & 5.03 & 5.16 & 0.0632 & 0 & 1 & 5.02 & 5.04 & 0.0479 & 0 & 1 \\
\hline FS & 45.19 & 46.83 & 0.7830 & 0 & 0.999 & 46.99 & 47.17 & 0.4368 & 0.01 & 1 \\
\hline Mike & 3.04 & 3.21 & 0.3560 & 0 & 0.998 & 3.12 & 3.14 & 0.1298 & 0 & 1 \\
\hline
\end{tabular}

TABLE VIII: RELATIONSHIP OF P-VALUE WITH STANDARD DEVIATION AND CONFIDENCE INTERVALS FOR GIZA 93

\begin{tabular}{|c|c|c|c|c|c|c|c|c|c|c|}
\hline \multirow[b]{2}{*}{ Traits } & \multicolumn{5}{|c|}{ HVI } & \multicolumn{5}{|c|}{$\mathrm{CCS}$} \\
\hline & $\begin{array}{l}\text { Lower } \\
95 \% \text { CI }\end{array}$ & $\begin{array}{c}\text { Upper } 95 \% \\
\text { CI }\end{array}$ & $\begin{array}{l}\text { Standard } \\
\text { deviation }\end{array}$ & $\mathrm{T}$ & $\mathrm{P}$ & $\begin{array}{l}\text { Lower } \\
95 \% \text { CI }\end{array}$ & $\begin{array}{c}\text { Upper } 95 \% \\
\text { CI }\end{array}$ & $\begin{array}{l}\text { Standard } \\
\text { deviation }\end{array}$ & $\mathrm{T}$ & $\mathrm{P}$ \\
\hline UHM & 33.65 & 34.27 & 0.2950 & 0 & 1 & 34.01 & 34.10 & 0.2243 & 0.01 & 0.993 \\
\hline $\mathrm{UI} \%$ & 83.25 & 84.54 & 0.6130 & 0 & 1 & 84.94 & 85.09 & 0.4000 & 0.01 & 0.994 \\
\hline $\mathrm{SFI} \%$ & 6.24 & 6.72 & 0.2317 & 0 & 1 & 6.49 & 6.57 & 0.2013 & 0 & 1 \\
\hline $\mathrm{E} \%$ & 5.33 & 5.59 & 0.1211 & 0 & 0.999 & 5.35 & 5.39 & 0.1026 & 0 & 1 \\
\hline FS & 40.30 & 41.69 & 0.6600 & 0 & 1 & 42.86 & 42.99 & 0.3412 & 0.01 & 0.993 \\
\hline Mike & 3.18 & 3.32 & 0.0280 & 0 & 0.998 & 3.07 & 3.12 & 0.0723 & 0.01 & 0.994 \\
\hline MR & 82.92 & 84.07 & 0.5480 & 0 & 1 & 84.62 & 84.70 & 0.2198 & 0.02 & 0.986 \\
\hline
\end{tabular}

As shown in Tables 6 and 7 for HVI measurements; the least coefficient of variation (C.V.) for maturity ratio (MR) in G 95 (Table 2); gives the narrow confidence interval by 83.98 and 84.16 meanwhile the highest C.V. was for UHM
(Table 2); gives the wider confidence interval by 28.89 and 30.02 .

In CCS measurements, the lowest (C.V.) was in maturity ratio (MR) for $\mathrm{G} 95$ in Table 2 gives narrow confidence 
interval with 84.49 and 84.53 although the highest C.V. was in SFI for G 93 which gives wider CI with 6.49 and 6.57 .

The degrees of wider confidence interval for CCS measurements were less than for HVI measurements (it is obvious in micronaire value (Mike); that depends on the larger sample size of CCS measurements as opposed to HVI measurements.

According to results, the size of the confidence interval depends on the sample size and the standard deviation of the cotton quality properties. If the sample size is large, this leads to more confidence and a narrower confidence interval such as in CCS measurements. The confidence interval is wide. This may mean that the sample is small such as in HVI measurements. If the dispersion is high, the conclusion is less certain, and the confidence interval becomes wider. The same results were agreed with [21].

Reliability refers to the extent to which a scale produces consistent results, if the measurements are repeated a number of times. Reliability analysis is determined by obtaining the proportion of systematic variation in a scale, which can be done by determining the association between the scores obtained from different administrations of the scale. Thus, if the association in reliability analysis is high, the scale yields consistent results and is therefore reliable [9], [23] and [34]. According to Tables 9 and 10, reliability analysis is used to measure the reliability of a summated scale (Cronbach's value) where several times are summated to form a total score. Furthermore, internal consistency reliability also called inter-observer reliability focuses on the internal consistency of the set of items forming the scale (Cronbach's value if item deleted).

Table 9 illustrated Cronbach's alpha was 75.700 and 78.022 for G 86 in HVI and CCS measurements, respectively. Where the minimum acceptable value for Cronbach's alpha 0.70 , below this value the internal consistency of the common range is low. Meanwhile the maximum expected value is 0.90 or above this value is perceived as redundancy or duplication according to [7], [15] and [28]. Where the value of Cronbach was more than 0.70 , which indicate good level of inter-consistency for the scale of the studied cotton quality properties. In HVI measurements, Cronbach's alpha if item deleted were in slightly increasing for FS by 0.115 (75.815-75.700) so there was no imperative use of Cronbach's alpha if item deleted. Meanwhile Cronbach in CCS measurements; UI\% increased by $2.122(80.144-78.022)$ followed by UHM increased by $1.478(79.500-78.022)$ and there was a slightly increase for E\% by 0.386 (78.408-78.022) so remove any items except UI\% and UHM would reset in a lower Cronbach's alpha. Furthermore, G 95 for both HVI and CCS measurements were elaborated in Table (9); Cronbach's alpha was 80.800 and 82.399 which indicated a high level of internal consistency for the current scale with all studied properties. But there is no real added value to use Cronbach's alpha if item deleted for both G 95 in HVI and CCS measurements.

TABLE IX: CRONBACH'S VALUES FOR INTERNAL RELIABILITY CONSISTENCY

\begin{tabular}{|c|c|c|c|c|c|c|c|c|}
\hline \multirow{3}{*}{ Traits } & \multicolumn{4}{|c|}{ G 86} & \multicolumn{4}{|c|}{ G 95} \\
\hline & \multicolumn{2}{|c|}{$\begin{array}{l}\text { Cronbach's } \\
\text { value }\end{array}$} & \multicolumn{2}{|c|}{$\begin{array}{c}\text { Cronbach's value if } \\
\text { item deleted }\end{array}$} & \multicolumn{2}{|c|}{$\begin{array}{l}\text { Cronbach's } \\
\text { value }\end{array}$} & \multicolumn{2}{|c|}{$\begin{array}{c}\text { Cronbach's value if } \\
\text { item deleted }\end{array}$} \\
\hline & HVI & $\mathrm{CCS}$ & HVI & $\mathrm{CCS}$ & HVI & $\mathrm{CCS}$ & HVI & CCS \\
\hline UHM & & & 74.643 & 79.500 & & & 80.564 & 81.565 \\
\hline $\mathrm{UI} \%$ & & & 75.529 & 80.144 & & & 80.667 & 73.500 \\
\hline SFI\% & & & 74.495 & 75.576 & & & 80.791 & 82.236 \\
\hline $\mathrm{E} \%$ & 75.700 & 78.022 & 75.038 & 78.408 & 80.800 & 82.399 & 80.870 & 81.750 \\
\hline FS & & & 75.815 & 73.740 & & & 80.066 & 82.298 \\
\hline Mike & & & 74.911 & 77.886 & & & 80.703 & 81.919 \\
\hline MR & & & 73.997 & 77.903 & & & 80.681 & 82.260 \\
\hline
\end{tabular}

Table 10 showed Cronbach's alpha was 79.422 and 81.254 for G 92 in HVI and CCS measurements, respectively; there were a slightly increase but it was not in use to apply Cronbach's alpha if item deleted. Adding to HVI and CCS measurements in G93, Cronbach's alpha values were 78.210 and 82.888 for HVI and CCS measurements and that indicates a high level of interconsistency for the scale of the summated cotton quality properties without the necessary for use Cronbach's alpha if item deleted. It is essentially for obtaining right decision to use more than one method. Therefore, applying descriptive statistics (measures of central tendency, measures of dispersion, skewness, and kurtosis), confidence interval for T-test and internal consistency reliability with each other give the vigor to the studied properties to put the correct decision for best recommendations; in measuring cotton quality properties from the selected homogenous cotton samples.

TABLEX: CRONBACH'S VALUES FOR INTERNAL RELIABILITY CONSISTENCY

\begin{tabular}{|c|c|c|c|c|c|c|c|c|}
\hline \multirow{3}{*}{ Traits } & \multicolumn{4}{|c|}{ G 92} & \multicolumn{4}{|c|}{ G 93} \\
\hline & \multicolumn{2}{|c|}{$\begin{array}{l}\text { Cronbach's } \\
\text { value }\end{array}$} & \multicolumn{2}{|c|}{$\begin{array}{c}\text { Cronbach's value if } \\
\text { item deleted }\end{array}$} & \multicolumn{2}{|c|}{$\begin{array}{c}\text { Cronbach's } \\
\text { value }\end{array}$} & \multicolumn{2}{|c|}{$\begin{array}{c}\text { Cronbach's value if } \\
\text { item deleted }\end{array}$} \\
\hline & HVI & CCS & HVI & CCS & HVI & CCS & HVI & CCS \\
\hline UHM & & & 79.877 & 81.710 & & & 77.974 & 82.153 \\
\hline $\mathrm{UI} \%$ & & & 79.623 & 81.777 & & & 78.340 & 82.077 \\
\hline SFI\% & & & 80.665 & 81.872 & & & 78.201 & 82.824 \\
\hline $\mathrm{E} \%$ & 79.422 & 81.254 & 79.931 & 81.770 & 78.210 & 82.888 & 78.288 & 82.239 \\
\hline FS & & & 79.818 & 81.703 & & & 77.476 & 82.787 \\
\hline Mike & & & 79.818 & 81.721 & & & 78.113 & 82.408 \\
\hline MR & & & 78.251 & 81.691 & & & 78.091 & 82.749 \\
\hline
\end{tabular}




\section{CONCLUSION}

This study characterized four cotton varieties categories: long staple class (Giza 86 and Giza 95) and extra-long staple class (Giza 92 and Giza 93) within the Egyptian base cotton grade Good. Data were measured by two different apparatus namely: High Volume Instrument (HVI) in Germany and Cotton Classifying System (CCS) in Egypt. The main aim was how to standardize commercial Egyptian cotton using fiber properties such as UHM, UI, E\%, FS, Mike, and MR. Using combination of several basic statistic methods to describe how close to homogeneity and to put a whole panorama for each studied variety. Using center of data (mean, Tr. Mean and median) to measure how data for each cotton variety distributed from the center, skewness to measure symmetry of distribution, kurtosis to measure combined size of the two tails. Adding to T-test and P-value to describe how close of cotton variety data to null hypothesis (degree of homogeneity). Moreover, put both lower and upper confidence interval. Finally, using Cronbach value to measure the reliability of all cotton fiber properties with each other to obtain the proportion of systematic variation in a scale. In terms of applied all previous statistic methods detected that CCS measurements were more homogeneous than HVI measurements.

It is hoped this search be the light for each Egyptian variety with their grades and below grades in creating local reference (standardized reference for cotton quality measurement instruments) then switch it from domestic to formal accreditation. Descriptive statistics (measures of central tendency, measures of dispersion, skewness, and kurtosis), confidence interval for T-test and internal consistency reliability with each other provide complementary information about the statistical probability and conclusions regarding the cotton varieties significance of study cotton homogeneity of findings.

\section{ACKNOWLEDGMENT}

The authors express their utmost gratitude and appreciation to Science \& Technology Development Fund (STDF) and Egyptian \& International Cotton Classification Center (EICCC) at Cotton Research Institute (CRT) at ARC, Egypt for providing up to date laboratory apparatus. Sincere thanks and grateful go to colleges of cotton grading department.

\section{REFERENCES}

[1] ASTM, ASTM standard D1776/D1776M-16, Standard practice for conditioning and testing textiles, ASTM International, west Conshohocken, 2016, pp. 1-5.

[2] J. Beyeneand, and R. Moineddin, "Methods for confidence interval estimation of a ratio parameter with application to location quotients," MBC Medical Research Methodology. Vol. 5, no. 32, pp. 1-7, 2005.

[3] M. Blank, and J. Peacock, "Interpreting statistics with confidence," The Obstetrician and Gynaecologist. Vol. 4, pp. 176-180, 2002.

[4] J. M. Bradow, L. H. Wartelle, P. J. Bauer, and G. F. Sassenrath-Cole, "Small sample cotton fiber quality quantitation," Cotton Science. Vol. 1, pp. 48-60, 1997.

[5] J. W. Bradow, and G. H. Davidonis, "Quantization of fiber quality and the cotton production processing interface: A physiologist's perspective," Cotton Science. Vol. 4, pp. 34-64, 2000.
[6] Corporate fiber and materials methodology, Fiber convention Methodology, 2019, pp. 1-14.

[7] L. J. Cronbach, "Coefficient alpha and the internal structure of tests," Psychometrika, vol. 16, no. 3, pp. 297-334, 2019.

[8] C. Duncan, "Basic statistics for social research," Routledge, 1997.

[9] S. Ellison, and A. Williams, "Measurement uncertainty: The key to use of recovery factors, the use of recovery factors in trace analyses," Ed M Parkany, pp. 30-37, 1996.

[10] Global Agricultural Information Network (GAIN) report Cotton and product annual, Gain report number: EG18011, 2018, pp. 1-14.

[11] Guideline for standardized instrument testing of cotton, International Cotton Advisory Committee (ICAC) task force on Commercial Standardization of Instrument Testing of Cotton (CSITC) and International Textile Manufacturers Federation (ITMF) International Committee on Cotton Testing Methods (ICCTM), 2018, pp. 1-45.

[12] N. Hirpara, S. Jain, A. Gupta, and S. D. Intern, "Interpretation research findings with confidence interval," Orthodontics and Endodontics, vol. 1, pp. 1-8, 2015.

[13] T. T. Houle, "Importance of effect sizes for the accumulation of knowledge, "Anesthesiology, vol. 106, pp. 415-417, 2007.

[14] S. Jain, P. R. Punyani, and D. Jain, " Basic of interpreting results," Dent. Med. Advanced Research, vol. 1, pp. 1-4, 2015.

[15] R. G. Jansen, L. F. Wiertz, E. S. Meyer, and L. P. Noldus,"Reliability analysis of observational data: problems, solutions and software implementation," Behavior Research Methods, Instruments and Computers, vol. 35, no. 3, pp.391-399, 2003.

[16] D. N. Joanes, and C. A. Gill, "Comparing measures of sample skewness and kurtosis," The Statistician, vol. 47, no.1, pp. 183-189, 1998.

[17] R. W. Mathangadeera, E. F. Hequet, B. Kelly, J. K. Dever, and C. M. Kell, "Importance of cotton fiber elongation in fiber processing," Industrial Crops and Products, pp.1-7, 2020.

[18] J. P. S. Moarais, B. R. Kelly, A. Sayeed, and E. F. Hequet,"Effects of non-lint material on heritability estimates of cotton fiber length parameters," Euphytica, vol. 216, no. 24, pp. 1-32, 2020.

[19] Minitab, Reference guide. Prepared for MATH201/MATH202, Bryan Crissinger, University of Delaware. Department of Mathematical Science, 2016.

[20] H. H. Perkins, Jr. D. E. Ethridge, and C. K. Bragg, "Cotton. $2^{\text {nd }}$ ed. Longman Scientific and Technical," Harlow, Essex, UK, 1984.

[21] M. Puth, M. Neuhauser, and G. D. Ruxton," On the variety of methods for calculating confidence intervals by bootstrapping," Animal Ecology, vol.84, pp. 892-897, 2015.

[22] T. Raykov,"Estimation of composite reliability for congeneric measures," Applied Psychological Measurement, vol. 21, no. 2, pp. 173-184, 1997.

[23] T. Raykov,"Coefficient alpha and composite reliability with interrelated nonhomogeneous items," Applied Psychological Measurement, vol. 22, no. 4, pp. 375-385, 1998.

[24] J. Rogers, J. Zumba, and C. Fortier, "Measurement comparison of cotton fiber micronaire and its components by portable near infrared spectroscopy instruments," Textile Research, vol. 87, no. 1, pp. 57-69, 2016.

[25] L. Schruben,"Confidence interval estimation using standardized time series," Operations Research, vol. 31, no. 6, pp.1090-1108, 1983.

[26] G. Shieh, "Confidence intervals and sample size calculations for the standardized mean difference effect size between two normal populations under heteroscedasticity," Behavior Research, vol.45, pp.955-967, 2013.

[27] SPSS, IBM SPSS Statistics 21 Core System. User's Guide (edited by IBM $₫$ SPSS $®$ statistics 21$)$, U. S. government users restricted rights by GSA and ADP, 2012.

[28] I. Shigeo, "Weights and measures in the Indus valley," Encyclopedia of the history of science Technology and medicine in non-western cultures, 2nd ed., Helaine Selin, 2008, PP.2254-2255.

[29] R. G. D. Steel, and J. H. Torrie, "Principles and procedures of statistics," McGraw- Hill Book Co., 1980, New York.

[30] Textile Testing Technology Group (TEXTECHNO), Textile Herbert Stein GmbH\& Co. KG, D-41066 Monchengladbach, Germany (www.textechno.com) and Lenzing Instruments GmbH \& Co. KG, A4860 Lenzing, Austria (www.lenzing-instruments.com).

[31] D. Thibodeaux, H. Senter, J. L. Knowlton, D. McAlister, and X. Cui, "A comparison of methods for measuring the short fiber content of cotton," Cotton Science, vol. 12, pp.298-305, 2008.

[32] B. L. Welch, "On confidence limits and sufficiency, with particular reference to parameters of locations," The Annuals of Mathematical Statistics, Vol.10, no.1, pp. 58-69, 1939.

[33] P. H. Westfall, "Kurtosis as peakedness," The American Statistician, vol. 86, no.3, pp. 191-195, 2014. 
European Journal of Agriculture and Food Sciences www.ejfood.org

[34] P. R. Yarnold, and R. C. Soltysik, "Reliability analysis in P. R. Yarnold \& R. C. Soltysik (Eds.), optimal data analysis: A guide book with software for windows," Washington, DC: American Psychological Association, 2005, pp. 121-140.

[35] S. Zandarov, "Textechno Publications," Advanced Industrial and Engineering Polymer Research, vol. 1, no.1, pp. 82-92, 2018.

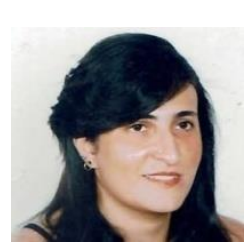

$\mathrm{ARC}$

Mona Shalaby was born on $16^{\text {th }}$ march, 1977 in Sweden. She has master (2007) and Ph. D. (2015) in applied statistics from Faculty of Agriculture in Cairo university. She is currently a researcher in Cotton Grading Section. Cotton Research Institute at Agricultural Research Center (ARC), Egypt. Formerly, she was a researcher at Central Laboratory for Design and Statistical Analyses, 